\title{
Efeito da suplementação com biotina sobre a concentração plasmática de glicose em bezerras mestiças - resultados parciais
}

Paulo José Bastos Queiroz, Yasmim Martins Emerich Pazini, Ana Paula de Almeida Vinhal, Matheus Furtado Pereira, Wanessa Patrícia Rodrigues da Silva, Luiz Antônio Franco da Silva

Escola de Veterinária e Zootecnia, Universidade Federal de Goiás (UFG), Goiânia, GO, Brasil

*Autor correspondente

e-mail: paulojose.vet@hotmail.com

\section{Resumo}

\begin{abstract}
A biotina é uma vitamina hidrossolúvel do complexo B, de grande importância para a gliconeogene, pois catalisa a primeira reação dessa via metabólica. Além disso, a biotina atua na via metabólica de transformação do propionato em glicose, que nos ruminantes é uma via importante de síntese de glicose. Estudos sobre a suplementação com biotina em bovinos demonstraram que essa vitamina pode promover aumento da produção de leite, mas o mecanismo fisiológico que ocasiona esse efeito ainda não foi esclarecido. 0 aumento da taxa de gliconeogenese promovido pela suplementação dessa vitamina é uma das teorias que podem explicar o aumento da produção leiteira. Este estudo objetivou avaliar o efeito da suplementação com biotina na concentração plasmática de glicose em bezerras mestiças (Jersey x Holandês) desmamadas. 0 estudo foi desenvolvido na Escola de Veterinária e Zootecnia da Universidade Federal de Goiás após aprovação do CEUA/ UFG, processo número 089/2015. Foram utilizadas 12 bezerras mestiças (Jersey X Holandês), saudáveis, 6 meses de idade e peso médio de $124,08 \pm 16,57$. As bezerras foram divididas em tratamento controle (TC) e tratamento biotina (GB), contendo seis animais em cada tratamento. Os animais do TB foram tratados com uma dose individual e diária de $20 \mathrm{mg}$ de biotina fornecida por via oral, enquanto o TC não recebeu nenhum tratamento. A avaliação laboratorial foi realizada em dois momentos distintos: um dia antes do início do fornecimento de biotina (T0) e no dia 60 (T1). As amostras de sangue foram colhidas 30 minutos antes da alimentação, por punção jugular, em tubos contendo fluoreto de sódio. Para avaliação da glicose plasmática utilizou-se metodologia cinética por meio do método enzimático. Empregou-se a análise de variância e o teste de Duncan, com nível de significância de 5\% para comparação das médias. Em T0, o TC apresentou glicemia média de 89,66 $\pm 7,09 \mathrm{mg} / \mathrm{dL}$ e o TB 91,83 $\pm 11,13 \mathrm{mg} / \mathrm{dL}$. Em T1, o TC apresentou glicose plasmática média de $94,82 \pm 8,08 \mathrm{mg} / \mathrm{dL}$, enquanto no TB observou-se $96,50 \pm 6,57 \mathrm{mg} / \mathrm{dL}$. Não houve diferença estatística entre os grupos pelo teste de Duncan $(\mathrm{P}>0,05)$. 0 efeito da suplementação com biotina sobre a glicemia de bovinos tem
\end{abstract}


apresentado resultados controversos. A glicose é um metabólico que sofre intenso controle endócrino. Dessa forma, em animais saudáveis, a suplementação de substâncias envolvidas na gliconeogênese não ocasionam, na maioria das vezes, variação glicêmica, pois a glicose sintetizada é desviada para o aumento da produção ou armazenada na forma de glicogênio. Conclui-se que a suplementação com $20 \mathrm{mg}$ de biotina durante 60 dias não interfere na concentração plasmática de glicose em bezerras mestiças (Jersey x Holandês) desmamadas. 